\section{SOI: 1.1/TAS DOI: 10.15863/TAS International Scientific Journal Theoretical \& Applied Science}

p-ISSN: 2308-4944 (print) e-ISSN: 2409-0085 (online)

Year: 2018 Issue: 09 Volume: 65

Published: $24.09 .2018 \quad \underline{\text { http://T-Science.org }}$
Muhammad Ayub

Dr., Assistant Professor in DHQ Teaching Hospital Gujranwala

Medical College Gujranwala, Pakistan mnaich@ hotmail.com

Kanwal Nasir Dr., WMO in DHQ Nankana Sahib, Pakistan. kanwalllnasir43@gmail.com

Zahra Aleem Dr., Doctor in Jinnah Hospital Lahore, Pakistan za_al@live.com

\title{
POSITIVE ROLE OF PHYSICAL ACTIVITY IN PATIENTS WITH GERD
}

\author{
Abstract: Objective: Objective of this study was to determine significance of physical activity in controlling \\ symptoms of gastroesophageal reflux disease. \\ Design and Setting: This is a cross sectional study. This study was conducted in DHQ Teaching Hospital \\ Gujranwala Medical College Gujranwala, Pakistan. \\ Duration: Study was started in January 2018 and completed in December 2018 consisted on 7 months \\ duration.
}

Patients and Methods: Total 600 cases were selected randomly from the attendants or relatives of patients who were living in the study hospital with their patients. A Performa was designed containing all necessary questions like age, gender, GERD symptoms, physical activity, time interval between dinner and going to bed to sleep. Ages of these patients were ranging from 20 to 75 years with mean age of 49.8 years. Mostly patients with GERD symptoms were above 45 years of age and they were not having habit of physical activity after taking meal. Cases with co-morbidities like heart, renal or liver disease and history of smoking or alcoholism or taking drug for any disease in previous six months were not included in the study. Sample size was calculated according to prevalence of disease $28 \%$. With the help of Doctors of each ward questionnaire was translated into language of the subject and their answers were noted down. Cases were distributed into two main groups, those having GERD symptoms were kept in one group and those not having symptoms were kept in separate group. Data from both groups was obtained and calculated in the form of frequencies and percentage. Data was analyzed using Microsoft office and SPSS version 2014. Results were presented in the form of frequency tables and graphs.

Results: There were 600 cases in this study. Out of them 260(43.3\%) cases were having symptoms of GERD and 340(56.7\%) were not having symptoms. In age group of 20-30 years 38.3\% were having symptoms and $61.6 \%$ did not. Similarly between ages of 31-40 years in 43.7\% cases symptoms were present and in 56.3\% were absent, in age group 41-50 years 45.4\% had symptoms, in cases with 51-60 years age 43.6\% had symptoms, 44.2\% cases in $60-70$ years age group were having symptoms and in $46.9 \%$ cases above 70 years of age were suffering from symptoms of GERD. There were 51\% female cases with GERD symptoms out of total 303 cases and $35.4 \%$ cases from 297 males gave history of GERD symptoms. It was seen that mostly cases with gastroesophageal disease belonged to male population. These symptoms were less in those cases that used to take physical activity after meals and go to bed 4 hours after dinner in $74.1 \%$ out of 193 cases. Most common symptom was retrosternal or epigastric pain or burning sensation in $75.4 \%$ cases out of those with GERD. Bitter or sour taste was reported in $49.6 \%$ and chronic cough due to reflux disease were found in $14.2 \%$ cases.

Conclusion: Gastroesophageal disease is very common problem mostly in male population. It is most common in old age. Post meal physical activity and delay in sleep after having dinner reduces symptoms of GERD.

Key words: Gastroesophageal reflux disease, retrosternal burning, Post meal Physical activity.

Language: English

Citation: Ayub M, Nasir K, Aleem Z (2018) POSITIVE ROLE OF PHYSICAL ACTIVITY IN PATIENTS WITH GERD. ISJ Theoretical \& Applied Science, 09 (65): 112-117.

Soi: http://s-o-i.org/1.1/TAS-09-65-17 Doi: crossef https://dx.doi.org/10.15863/TAS.2018.09.65.17

\section{INTRODUCTION}

Our daily unhealthy routine life has made us prone to many diseases. Due to lack of proper physical activity gastrointestinal diseases occur. ${ }^{1}$ Most common GI disease is gastroesophageal reflux disease. This disease is associated with unhealthy life style such as insufficient physical activity; smoking, alcoholism and stress are main risk factors. In this study we determined role of physical activity in reducing incidence of gastroesophageal reflux 
disease and minimizing symptoms in patients with GERD disease. ${ }^{2,3}$ Patients with GERD has symptoms of retrosternal burning, chest pain, epigastric pain, sour throat, bitter taste, chronic cough due to chronic GERD etc. This disease has high prevalence in Asian countries as compared to European countries. Causes of this disease are decreased lower esophageal sphincter tone, delayed gastric emptying or diaphragmatic hernia. This disease can be prevented by healthy life style such as post meal walk, increasing time interval between meal and sleeping, cessation of smoking, coffe, tea, avoid of extra stress and use of healthy food. ${ }^{4}$ There are various investigations to evaluate cause of disease such as esophageal manometry and $24 \mathrm{hr} \mathrm{PH}$ monitoring, endoscopy and chest $\mathrm{x}$ ray for evaluating diaphragmatic hernia. People of Asian countries have more prevalence of this problem because of stressful working environment, congestive working places promoting stress and financial issues mostly in people of underdeveloped countries like Pakistan, India and Nepal. This problem is more common among the people of low socioeconomic status. ${ }^{5-}$ ${ }^{6}$ Treatment of GERD includes post meal walk, body posture while sleeping, 3-4 hours interval between dinner and sleep, use of $\mathrm{H} 2$ blockers and Omeprazole. Long duration of GERD may lead to complications such as chronic cough, exacerbation of asthma, barret esophagus, middle ear infection, body weakness due to indigestion of food and decreased body immunity. Obesity is associated with GERD. Such people should reduce weight to get rid of gastroesophageal reflux disease. Ethnicity, climate, physical parameters are associated with incidence of this disease. Many studies have been done on presenting symptoms of GERD and its management but less work has been done on its associated factors and causes. ${ }^{7,8}$ According to studies conducted in western developed countries results were different from our study. Other differential diagnosis of such patients with GERD may be Peptic ulcer disease, gastric outlet obstruction, pyloric stenosis, diaphragmatic hernia or esophageal motility disorder. Change of life style is very important in controlling GERD symptoms.

\section{Patients and Methods}

This is a cross sectional study done in a teaching hospital. This study was completed in a duration of 7 months. Total 600 cases were selected randomly from the attendants or relatives of patients who were living in the study hospital with their patients. . Most common GI disease is gastroesophageal reflux disease. This disease is associated with unhealthy life style such as insufficient physical activity; smoking, alcoholism and stress are main risk factors. In this study we determined role of physical activity in reducing incidence of gastroesophageal reflux disease and minimizing symptoms in patients with GERD disease. A Performa was designed containing all necessary questions like age, gender, GERD symptoms, physical activity, time interval between dinner and going to bed to sleep. Ages of these patients were ranging from 20 to 75 years with mean age of 49.8 years. Mostly patients with GERD symptoms were above 45 years of age and they were not having habit of physical activity after taking meal. Cases with co-morbidities like heart, renal or liver disease and history of smoking or alcoholism or taking drug for any disease in previous six months were not included in the study. Sample size was calculated according to prevalence of disease $28 \%$. With the help of Doctors of each ward questionnaire was translated into language of the subject and their answers were noted down. Cases were distributed into two main groups, those having GERD symptoms were kept in one group and those not having symptoms were kept in separate group. Data from both groups was obtained and calculated in the form of frequencies and percentage. Data was analyzed using Microsoft office and SPSS version 2014. Results were presented in the form of frequency tables and graphs. Those patient having other diseases such as CKD, CLD. IHD, tuberculosis or any other disease associated with GERD were not included in this study. Only those cases were included who were not having any other chronic disease and no history of smoking or alcoholism, NSAIDs or aspirin use in last six months.

\section{Results}

There were 600 cases in this study. Out of them $260(43.3 \%)$ cases were having symptoms of GERD and $340(56.7 \%)$ were not having symptoms. In age group of 20-30 years 23(38.3\%) were having symptoms and $37(61.6 \%)$ did not. Similarly between ages of $31-40$ years in $38(43.7 \%)$ cases symptoms were present and in $49(56.3 \%)$ were absent, in age group 41-50 years 55(45.4\%) had symptoms, in cases with 51-60 years age 68(43.6\%) had symptoms, $46(44.2 \%)$ cases in 60-70 years age group were having symptoms and in $30(46.9 \%)$ cases above 70 years of age were suffering from symptoms of GERD. There were $155(51 \%)$ male cases with GERD symptoms out of total 303 cases and $105(35.4 \%)$ cases from 297 females gave history of GERD symptoms. It was seen that mostly cases with gastroesophageal disease belonged to male population. These symptoms were less in those cases that used to take physical activity after meals and go to bed 4 hours after dinner in 143(74.1\%) out of 193 cases. Most common symptom was retrosternal or epigastric pain or burning sensation in 196(75.4\%) cases out of those with GERD. Bitter or sour taste was reported in 129(49.6\%) and chronic cough due to reflux disease were found in $37(14.2 \%)$ cases. In 


\begin{tabular}{|c|c|c|c|c|c|c|}
\hline \multirow{4}{*}{ Impact Factor: } & ISRA (India) & $=1.344$ & SIS (USA) & $=0.912$ & ICV (Poland) & $=6.630$ \\
\hline & ISI (Dubai, UAE & $=0.829$ & РИНЦ (Russia) & $=0.156$ & PIF (India) & $=1.940$ \\
\hline & GIF (Australia) & $=0.564$ & ESJI (KZ) & $=4.102$ & IBI (India) & $=4.260$ \\
\hline & JIF & $=1.500$ & SJIF (Morocco & $=2.031$ & & \\
\hline
\end{tabular}

$177(68.1 \%)$ cases sleep disturbance due to GERD was reported. Out of 260 cases having symptoms $80(69 \%)$ cases gave history of dinner-bed interval of one hour or less. These cases are more prone to this problem. This value was $64(45.1 \%)$ with dinner-bed interval of 2 hours and in 66(44.3\%) cases with symptoms of GERD interval between dinner and sleep was 3 hours.

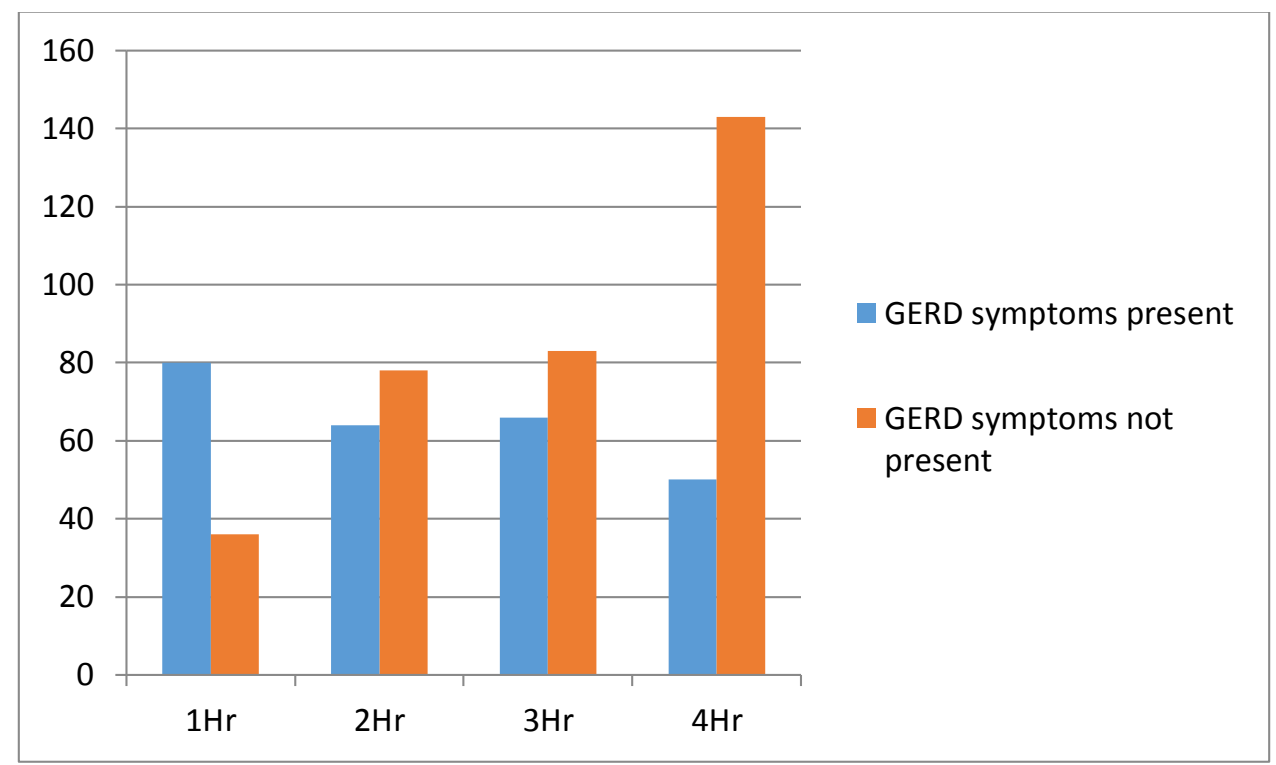

Figure-1 Association of interval between dinner and bed time to GERD symptoms

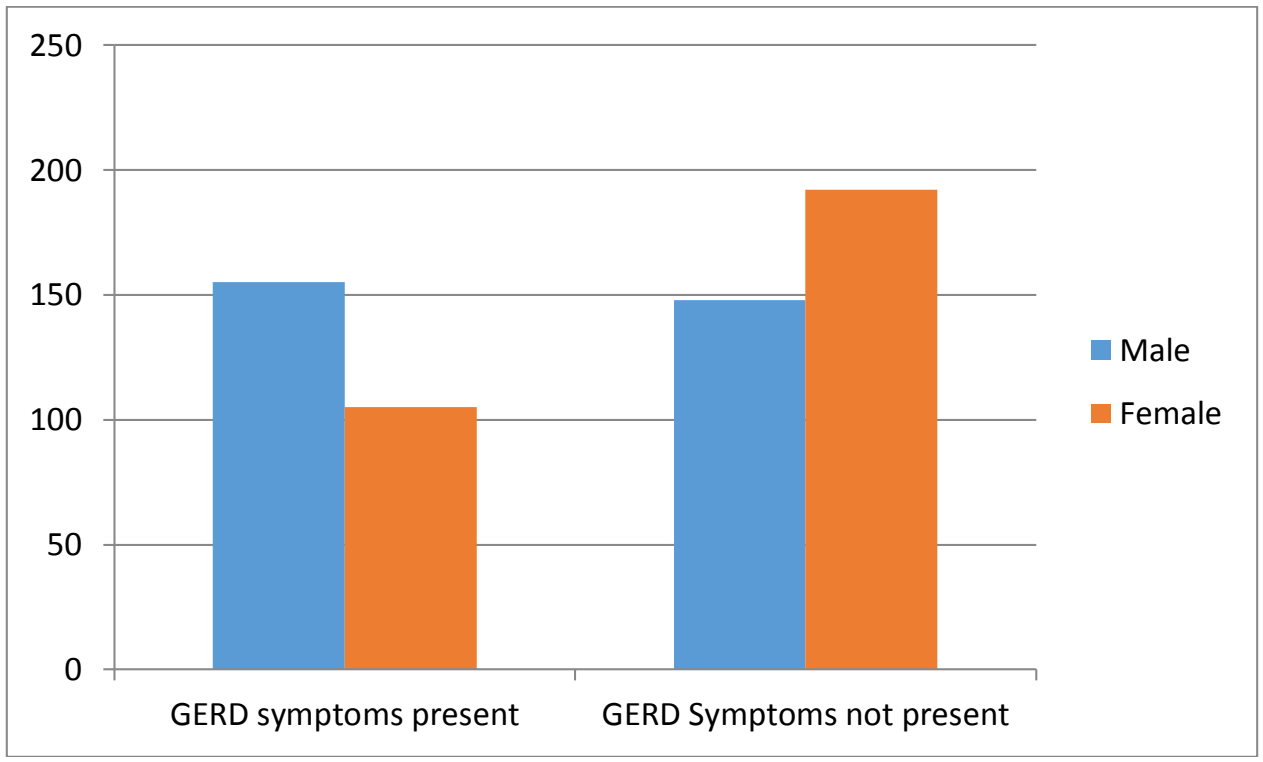

Figure-2 Association of Gender with incidence of GERD 


\begin{tabular}{l|lr|ll|ll} 
& ISRA (India) & $=\mathbf{1 . 3 4 4}$ & SIS (USA) & $=\mathbf{0 . 9 1 2}$ & ICV (Poland) & $=\mathbf{6 . 6 3 0}$ \\
Impact Factor: & ISI (Dubai, UAE) $=\mathbf{0 . 8 2 9}$ & PUHЦ (Russia) $=\mathbf{0 . 1 5 6}$ & PIF (India) & $=\mathbf{1 . 9 4 0}$ \\
& GIF (Australia) & $\mathbf{0 . 5 6 4}$ & ESJI (KZ) & $=4.102$ & IBI (India) & $=\mathbf{4 . 2 6 0}$ \\
& JIF & $=\mathbf{1 . 5 0 0}$ & SJIF (Morocco) & $=2.031$ & & \\
\hline
\end{tabular}

Age distribution among the cases with GERD in study group

\begin{tabular}{|c|c|c|c|c|c|}
\hline $\begin{array}{c}\text { Age of patients } \\
\text { (Years) }\end{array}$ & \multicolumn{2}{|c|}{ GERD symptoms present } & \multicolumn{2}{c|}{ GERD symptoms not present } & Total \\
\hline $20-30$ & $\mathbf{N}$ & $\mathbf{\%}$ & $\mathbf{N}$ & $\mathbf{\%}$ & \\
\hline $31-40$ & 23 & 38.3 & 37 & 61.6 & $\mathbf{6 0}$ \\
\hline $41-50$ & 38 & 43.7 & 49 & 56.3 & $\mathbf{8 7}$ \\
\hline $51-60$ & 55 & 45.4 & 74 & 57.4 & $\mathbf{1 2 9}$ \\
\hline $61-70$ & 68 & 43.6 & 88 & 56.4 & $\mathbf{1 5 6}$ \\
\hline Above 70 & 46 & 44.2 & 58 & 55.8 & $\mathbf{1 0 4}$ \\
\hline
\end{tabular}

Frequency of various symptoms of gastroesophageal reflux disease among study cases

\begin{tabular}{|l|c|c|}
\hline \multicolumn{1}{|c|}{ GERD Symptoms } & Number of Patients & \% \\
\hline Chest burn sensation & 196 & 75.4 \\
\hline Bitter or sour taste & 129 & 49.6 \\
\hline Chronic cough due to GERD & 37 & 14.2 \\
\hline Disturbed sleep due to reflux & 177 & 68.1 \\
\hline
\end{tabular}

\section{DISCUSSION}

Gastroesophageal reflux disease is very common among people living unhealthy life style using coffe, tea and smoking, alcoholism. ${ }^{9,10}$ Lack of physical activity is a major factor determining its incidence. Male population has more incidence than female population. It is more prevalent among old people than adults or young. Our daily unhealthy routine life has made us prone to many diseases. Due to lack of proper physical activity gastrointestinal diseases occur. Most common GI disease is gastroesophageal reflux disease. ${ }^{11}$ This disease is associated with unhealthy life style such as insufficient physical activity; smoking, alcoholism and stress are main risk factors. In this study we determined role of physical activity in reducing incidence of gastroesophageal reflux disease and minimizing symptoms in patients with GERD disease. ${ }^{12-15}$ Patients with GERD has symptoms of retrosternal burning, chest pain, epigastric pain, sour throat, bitter taste, chronic cough due to chronic GERD etc. This is a cross sectional study done in a teaching hospital. This study was completed in duration of 7 months. Total 600 cases were selected randomly from the attendants or relatives of patients who were living in the study hospital with their patients. . Most common GI disease is gastroesophageal reflux disease. This disease is associated with unhealthy life style such as insufficient physical activity; smoking, alcoholism and stress are main risk factors. ${ }^{16}$ In this study we determined role of physical activity in reducing incidence of gastroesophageal reflux disease and minimizing symptoms in patients with GERD disease. A Performa was designed containing all necessary questions like age, gender, GERD symptoms, physical activity, time interval between dinner and going to bed to sleep. Ages of these patients were ranging from 20 to 75 years with mean age of 49.8 years. ${ }^{17,18}$ There were $155(51 \%)$ male cases with GERD symptoms out of total 303 cases and $105(35.4 \%)$ cases from 297 females gave history of GERD symptoms. It was seen that mostly cases with gastroesophageal disease belonged to male 
population. These symptoms were less in those cases that used to take physical activity after meals and go to bed 4 hours after dinner in $143(74.1 \%$ ) out of 193 cases. Most common symptom was retrosternal or epigastric pain or burning sensation in 196(75.4\%) cases out of those with GERD. Bitter or sour taste was reported in 129(49.6\%) and chronic cough due to reflux disease were found in $37(14.2 \%)$ cases. Treatment of GERD includes post meal walk, body posture while sleeping, 3-4 hours interval between dinner and sleep, use of $\mathrm{H} 2$ blockers and Omeprazole. ${ }^{19,20}$ Long duration of GERD may lead to complications such as chronic cough, exacerbation of asthma, barret esophagus, middle ear infection, body weakness due to indigestion of food and decreased body immunity. Obesity is associated with GERD. Such people should reduce weight to get rid of gastroesophageal reflux disease. Ethnicity, climate, physical parameters are associated with incidence of this disease. ${ }^{21,22}$ Many studies have been done on presenting symptoms of GERD and its management but less work has been done on its associated factors and causes.

\section{CONCLUSION}

GERD is a very common disease among male population and older people which can be prevented by healthy lifestyle such as proper physical activity daily especially after taking meal and before going to bed. Cessation of smoking, avoiding coffe and tea, walk after taking dinner and interval between dinner and sleep 3-4 hours are associated with decrease in GERD symptoms. Public awareness can play a main ole in decreasing its incidence.

\section{References:}

1. DeVault KR, Castell DO, (2005) American College of Gastroenterology. Updated guidelines for the diagnosis and treatment of gastroesophageal reflux disease. Am J Gastroenterol 2005; 100: 190-200.

2. Fock KM, Talley N, Hunt R, Fass R, Nandurkar S, Lam SK, et al. (2004) Report of the AsiaPacific consensus on the management of gastroesophageal reflux disease. J Gastroenterol Hepatol 2004; 19: 357-67.

3. Goh KL, Chang CS, Fock KM, Ke M, Park HJ, Lam SK. (2000) Gastro-oesophageal reflux disease in Asia. J Gastroenterol Hepatol 2000; 15: 230-8.

4. Dent J, El-Serag HB, Wallander MA, Johansson S. (2005) Epidemiology of gastrooesophageal reflux disease: a systematic review. Gut 2005; 54: 710-7.

5. Jafri N, Jafri W, Yakoob J, Islam M, Manzoor S, Jalil A, et al. (2005) Perception of gastroesophageal reflux disease in urban population in Pakistan. J Coll Physicians Surg Pak 2005; 15: 532-4.

6. Knipschild P. (1990) Symptoms in gastrooesophageal reflux. Lancet 1990; 335: 971.

7. Festi D, Scaioli E, Baldi F, Vestito A, Pasqui F, Di Biase AR, et al. (2009) Body weight, lifestyle, dietary habits and gastroesophageal reflux disease. World J Gastroenterol 2009; 15: 1690-701.

8. Vakil N, van Zanten SV, Kahrilas P, Dent J, Jones R, (2006) Global Consensus Group. The
Montreal definition and classification of gastroesophageal reflux disease: a global evidence-based consensus. Am J Gastroenterol 2006; 101: 1900-20.

9. Nilsson M, Johnsen R, Ye W, Hveem K, Lagergren J. (2004) Prevalence of gastrooesophageal reflux symptoms and the influence of age and sex. Scand J Gastroenterol 2004; 39: 1040-5.

10. Moayyedi P, Talley NJ. (2006) Gastrooesophageal reflux disease. Lancet 2006; 367 : 2086-100.

11. Katz LC, Just R, Castell DO. (1994) Body position affects recumbent postprandial reflux. J Clin Gastroenterol 1994; 18: 280-3.

12. Pehl C, Wendl B, Pfeiffer A, Schmidt T, Kaess H. (1993) Low-proof alcoholic beverages and gastroesophageal reflux. Dig Dis Sci 1993; 38: 93-6.

13. Heading RC. (2004) Review article: diagnosis and clinical investigation of gastro-oesophageal reflux disease: a European view. Aliment Pharmacol Ther 2004; 20(Suppl 8): 9-13.

14. Locke GR 3rd, Talley NJ, Fett SL, Zinsmeister AR, Melton LJ 3rd. (1997) Prevalence and clinical spectrum of gastroesophageal reflux: a population-based study in Olmsted County, Minnesota. Gastroenterology 1997; 112: 144856.

15. Fujiwara Y, Machida A, Watanabe Y, Shiba M, Tominaga K, Watanabe T, et al. (2005) Association between dinner-to-bed time and 


\begin{tabular}{l|lr|ll|ll} 
& ISRA (India) & $=\mathbf{1 . 3 4 4}$ & SIS (USA) & $=\mathbf{0 . 9 1 2}$ & ICV (Poland) & $=\mathbf{6 . 6 3 0}$ \\
Impact Factor: & ISI (Dubai, UAE) $=\mathbf{0 . 8 2 9}$ & PUHЦ (Russia) $=\mathbf{0 . 1 5 6}$ & PIF (India) & $=\mathbf{1 . 9 4 0}$ \\
& GIF (Australia) & $\mathbf{0 . 5 6 4}$ & ESJI (KZ) & $=4.102$ & IBI (India) & $=\mathbf{4 . 2 6 0}$ \\
& JIF & $=\mathbf{1 . 5 0 0}$ & SJIF (Morocco) & $=2.031$ & & \\
\hline
\end{tabular}

gastro-esophageal reflux disease. Am J Gastroenterol 2005; 100: 2633-6.

16. van Herwaarden MA, Katzka DA, Smout AJ, Samsom M, Gideon M, Castell DO. (2000) Effect of different recumbent positions on postprandial gastroesophageal reflux in normal subjects. Am J Gastroenterol 2000; 95: 2731-6.

17. Nilsson M, Johnsen R, Ye W, Hveem K, Lagergren J. (2004) Lifestyle related risk factors in the aetiology of gastro-oesophageal reflux. Gut 2004; 53: 1730-5.

18. Nocon M, Labenz J, Willich SN. (2006) Lifestyle factors and symptoms of gastrooesophageal reflux -- a population-based study. Aliment Pharmacol Ther 2006; 23: 169-74.

19. Dean BB, Crawley JA, Schmitt CM, Wong J, Ofman JJ. (2003) The burden of illness of gastro-oesophageal reflux disease: impact on work productivity. Aliment Pharmacol Ther 2003; 17: 1309-17.

20. Piesman M, Hwang I, Maydonovitch C, Wong RK. (2007) Nocturnal reflux episodes following the administration of a standardized meal. Does timing matter? Am J Gastroenterol 2007; 102: 2128-34.

21. Watanabe Y, Fujiwara Y, Shiba M, Watanabe $\mathrm{T}$, Tominaga K, Oshitani N, et al. (2003) Cigarette smoking and alcohol consumption associated with gastro-oesophageal reflux disease in Japanese men. Scand J Gastroenterol 2003; 38: 807-11.

22. Stermer E. (2002) Alcohol consumption and the gastrointestinal tract. Isr Med Assoc J 2002; 4: 200-2. 